\title{
Caracterização agronômica de populações locais de azevém na Região Sul do Brasil
}

\author{
Agronomic characterization of ryegrass landraces at Southern Brazil
}

\author{
Andréa Mittelmann' Daniel Portella Montardo ${ }^{\text {II }}$ Caroline Marques Castro ${ }^{\text {III }}$ \\ Cley Donizeti Martins Nunes ${ }^{\text {III }}$ Elizandra Döring Buchweitz ${ }^{\text {IV }}$ Bruna Obes Corrêa $^{\text {IV }}$
}

\section{RESUMO}

Populações locais são fonte de variabilidade genética e adaptação para os programas de melhoramento; entretanto, pouco se sabe sobre as populações de azevém anual naturalizadas na América do Sul. Os objetivos deste trabalho foram analisar um conjunto de populações locais de azevém para produção de matéria seca e outros caracteres de importância agronômica e verificar a divergência existente entre essas populações. Foram avaliadas 36 populações, em um delineamento de blocos casualizados com quatro repetições. A produção de matéria seca variou de 1752,53 a $3905,67 \mathrm{~kg} \mathrm{ha}^{-1}$, com dezenove populações no grupo superior e a cultivar 'BRS Ponteio' como primeira do ranking. As populações brasileiras de azevém diferem para produção de matéria seca, bem como para produção de matéria seca no inverno e é possivel identificar populações com ciclo produtivo mais longo.

Palavras-chave: recursos genéticos, forrageiras, populações locais, Lolium multiflorum Lam.

\section{ABSTRACT}

Landraces are an important source of genetic variability in breeding programs. In spite of this, little is known about South American Italian ryegrass populations. The objectives of this research were to characterize a group of Brazilian Landraces of Italian ryegrass for dry matter production and other traits of agronomic importance, and to study genetic divergence among them. Thirty-seven populations were evaluated in a randomized block design with four replications. Dry matter production varied from
1752.53 to $3905.67 \mathrm{~kg} \mathrm{ha}^{-1}$, with nineteen populations in the most productive group and 'BRS Ponteio' ranking as the first one. Brazilian ryegrass populations differ for dry matter production and winter dry matter production. Populations with longer vegetative cycle may be identified.

Key words: genetic resources, forage species, landraces, Lolium multiflorum Lam.

\section{INTRODUÇÃO}

Populações locais, as quais passaram por um longo período de adaptação ao ambiente e aos sistemas de produção, têm sido historicamente de grande utilidade para o melhoramento, especialmente em forrageiras (FRANKEL et al., 1995). Em geral, possuem grande diversidade genética e adaptação aos estresses bióticos e abióticos da região. No início dos programas de melhoramento do azevém perene na nova Zelândia, populações locais superaram todos os genótipos introduzidos (EASTON, 1980). Segundo este autor, ainda existe grande interesse na comercialização de variedades locais, em virtude de qualidades como adaptação local e resistência a pragas e doenças.

O azevém anual (Lolium multiflorum Lam.) é nativo do sul da Europa, norte da África e oeste da

'Embrapa Gado de Leite/Embrapa Clima Temperado. C.P. 403, 96001-970, Pelotas, RS,Brasil. E-mail: andream@cnpgl.embrapa.br. Autor para correspondência.

"Embrapa Pecuária Sul, Bagé, RS, Brasil.

IIIEmbrapa Clima Temperado, Pelotas, RS, Brasil.

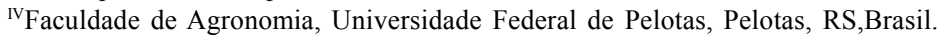


Ásia (NELSON et al., 1997). Na Região Sul do Brasil, foi introduzido por imigrantes, por volta de 1875 , estando hoje largamente disseminado. Um grande número de populações vem sendo mantidas sob ressemeadura natural, nas diferentes condições de clima, solo e sistemas de produção existentes nas Regiões Sul e Sudeste do Brasil. Populações naturalizadas de azevém são muito comuns na América do Sul, porém existe muito pouca informação sobre elas.

Em populações coletadas na Argentina, foi encontrada variabilidade para uma série de caracteres de importância agronômica, entre eles vigor, hábito de crescimento, ciclo e altura de planta (ROSSO \& ANDRÉS, 2001). Também, no Brasil, existem diferenças entre populações locais, indicando a possibilidade de seleção de populações mais produtivas e adaptadas às diferentes condições edafoclimáticas (DIAS et al., 2001; CASTRO et al., 2003; MITTELMANN et al., 2004).

Considerando a importância econômica da pecuária para a Região Sul do Brasil e a importância do azevém como espécie forrageira, este trabalho foi desenvolvido com os seguintes objetivos: 1) analisar um conjunto de populações locais de azevém quanto à produção de matéria seca e outros caracteres de importância agronômica; 2) verificar a divergência existente entre essas populações.

\section{MATERIAL E MÉTODOS}

Foram avaliadas 36 populações de azevém, sendo 28 pertencentes ao Banco Ativo de Germoplasma de Azevém da Embrapa Gado de Leite/ Embrapa Clima Temperado, identificadas numericamente, a cultivar 'BRS Ponteio', lançada pela Embrapa Clima Temperado em parceria com a Embrapa Gado de Leite e sete provenientes da Fepagro. Como testemunhas, foram utilizadas duas variedades comerciais: 'Comum' e 'LE 284'. Desta última, foram utilizadas sementes comerciais de duas procedências diferentes, identificadas como LE 284-1 (Uruguaiana) e LE 284-2 (Ijuí).

O experimento foi realizado na Estação Experimental Terras Baixas da Embrapa Clima Temperado, no município de Capão do Leão, Rio Grande do Sul, Brasil (31 $52^{\circ} 00^{\prime \prime}$ S, 52 $21^{\circ} 24^{\prime \prime}$ W, altitude 13,24 m). De acordo com a classificação de Köppen, o clima da região é do tipo subtropical úmido. O solo é um Planossolo hidromórfico (EMBRAPA, 1999). O delineamento experimental foi em blocos casualizados com quatro repetições, sendo cada parcela representada por uma linha de $3 \mathrm{~m}$ de comprimento. O espaçamento entre linhas foi de $0,3 \mathrm{~m}$ e a densidade de semeadura correspondente a $3 \mathrm{~g}$ de sementes viáveis por metro quadrado. $\mathrm{O}$ experimento foi semeado em 03/05/04 e foram realizados cortes mecânicos, sempre que as plantas atingiam $0,2 \mathrm{~m}$ de altura, deixando resíduo de $0,07 \mathrm{~m}$. A área útil consistiu dos $2 \mathrm{~m}$ centrais da linha. Após cada um dos três primeiros cortes, foi aplicado nitrogênio. Os cortes foram realizados nas seguintes datas: 28/07, 17/08, 09/ $09,13 / 10$ e $03 / 11$.

Nas três primeiras repetições, foram avaliados o vigor inicial (vigor) - nota de um a cinco, sendo $1=$ baixo vigor e $5=$ alto vigor, atribuída 60 dias após a semeadura; hábito de crescimento (hábito), avaliação visual, sendo $1=$ prostrado, $3=$ intermediário, $5=$ ereto; produção de matéria seca por corte (MS, $\mathrm{kg}$ $\mathrm{ha}^{-1}$ ) e produção acumulada de matéria seca (MS acumulada, $\mathrm{kg} / \mathrm{ha}$ ), soma da produção obtida em cada um dos cortes. Na quarta repetição, não foram realizados cortes. Os caracteres avaliados foram vigor inicial, ciclo (número de dias da semeadura à emissão das espigas em $50 \%$ das plantas da parcela), altura final das plantas (altura final, medida em centímetros, da superfície do solo até a base da folha bandeira), produção de sementes $\left(\mathrm{kg} \mathrm{ha}^{-1}\right)$, severidade da ferrugem do colmo (Puccinia graminis) e de manchas foliares. A avaliação de manchas foliares refere-se a um conjunto de sintomas causados por diversos agentes, dentre os quais houve o predomínio da mancha-parda (Cochliobolus sativus) As avaliações da ferrugem do colmo e manchas foliares foram feitas visualmente através de porcentagem de área foliar atacada (\%).

Para os caracteres avaliados em três repetições, foi realizada a análise de variância, utilizando o programa SAS (SAS INSTITUTE, 1990), e as médias das populações foram comparadas pelo teste de Scott-Knot, utilizando o programa Genes (CRUZ, 2001). A divergência entre as populações foi estudada por meio de análise de agrupamento pelo método da ligação média entre grupos (UPGMA), com base na distância Euclidiana média com dados padronizados. A importância relativa das variáveis para a divergência foi determinada conforme SINGH (1981). Essas análises foram realizadas utilizando o programa Genes (CRUZ, 2001).

\section{RESULTADOS E DISCUSSÃO}

Houve diferença entre as populações para todos os caracteres, exceto para o vigor inicial (Tabela 1). Os caracteres de maior interesse para o melhoramento do azevém são a produção acumulada de matéria seca e a produção nos primeiros cortes, 
Tabela 1 - Resumo da análise de variância para os caracteres vigor inicial, hábito de crescimento, produção de matéria seca (MS) por corte e produção acumulada de matéria seca. Capão do Leão, 2004.

\begin{tabular}{|c|c|c|c|c|c|c|c|c|}
\hline F.V. & Vigor & Hábito & $\begin{array}{l}\text { MS 1 corte } \\
\left(\mathrm{kg} \mathrm{ha}^{-1}\right)\end{array}$ & $\begin{array}{l}\text { MS } 2^{\circ} \text { corte } \\
\left(\mathrm{kg} \mathrm{ha}^{-1}\right)\end{array}$ & $\begin{array}{l}\text { MS } 3^{\circ} \text { corte } \\
\left(\mathrm{kg} \mathrm{ha}^{-1}\right)\end{array}$ & $\begin{array}{l}\text { MS } 4^{\circ} \text { corte } \\
\left(\mathrm{kg} \mathrm{ha}^{-1}\right)\end{array}$ & $\begin{array}{l}\text { MS 5o corte } \\
\left(\mathrm{kg} \mathrm{ha}^{-1}\right)\end{array}$ & $\begin{array}{l}\text { MS acumulada } \\
\quad\left(\mathrm{kg} \mathrm{ha}^{-1}\right)\end{array}$ \\
\hline Blocos & 0,56 & 1,43 & $95,43^{*}$ & $488638^{*}$ & 992380* & 93850 & 0,0725 & 2201 \\
\hline Populações & 0,65 & $3,14^{*}$ & $17,43^{*}$ & $57328 *$ & $65199 *$ & $217683^{*}$ & $0,2592^{*}$ & $548880^{*}$ \\
\hline Erro & 0,55 & 0,68 & 10,92 & 18686 & 28998 & 78884 & 0,0636 & 235721 \\
\hline C.V. & 23,43 & 23,31 & 21,61 & 19,67 & 19,25 & 27,90 & 12,38 & 16,14 \\
\hline $\mathrm{R}^{2}$ & 0,31 & 0,70 & 0,51 & 0,70 & 0,68 & 0,60 & 0,69 & 0,56 \\
\hline Média & 3,16 & 3,54 & 248,32 & 695,03 & 884,42 & 1006,78 & 146,58 & 3007,82 \\
\hline
\end{tabular}

F.V. = fontes de variação

* Significativo pelo teste $\mathrm{F}$ a $5 \%$ de probabilidade

que indica precocidade. Outro caráter que possibilita a avaliação de precocidade é o vigor. Embora não tenha havido diferença significativa para o vigor, houve significância do efeito de populações para a produção de matéria seca no primeiro corte (Tabela 1). Esse caráter variou de 100,67 a $386,67 \mathrm{~kg} \mathrm{ha}^{-1}$, embora essas diferenças não tenham sido significativas pelo teste de Scott-Knot (Tabela 2). Os valores foram semelhantes aos obtidos em outro experimento conduzido na região (MITTELMANN et al., 2004), assim como o número de dias decorrido da semeadura ao primeiro corte, que foi de 86 dias.

Outra abordagem adotada para a questão da produção precoce foi verificar a produção acumulada no período de inverno, a qual neste trabalho foi representada pelos três primeiros cortes. As populações 103, 130, 133, 135, 139, 142, 143, 144, $149,160,163,74,78$, Casca, Trovão e a testemunha 'Comum' estiveram no grupo superior para o segundo e terceiro cortes, representando materiais com boa produção hibernal (Tabela 2). As populações testadas tiveram de 50 a $79 \%$ de sua produção no período de inverno. Produções de inverno variando de 2327 a $3995 \mathrm{~kg} \mathrm{ha}^{-1}$, representando de 51 a $60 \%$ da produção acumulada das cultivares, foram obtidas no Planalto Catarinense (TCACENCO, 1989). Em outro estudo, o azevém ‘Comum' produziu de 48 a $58 \%$ da matéria seca total no período de inverno, sendo esse valor maior quando a semeadura ocorreu mais cedo (GOMES \& REIS, 1999).

A variação para produção no último corte foi grande, com a formação de três grupos, sendo a população Vacaria menos produtiva que todos os demais tratamentos. As testemunhas permaneceram no grupo intermediário (Tabela 2), havendo 23 populações significativamente superiores a elas. Este corte é importante, pois reflete a possibilidade de prolongamento do período de utilização da pastagem, o que é de grande interesse, especialmente em áreas permanentes de pastagem, onde não há um cultivo de verão. De maneira geral, parece haver uma ligação entre o rápido desenvolvimento inicial de uma população e o fato de florescer e cessar a produção mais cedo. Porém, já foi demonstrado que essa associação pode ser quebrada (MITTELMANN et al., 2006).

Em termos de produção acumulada ao longo de todo o período, foram formados dois grupos, com dezenove populações no grupo superior, produzindo acima de três mil quilos de matéria seca por hectare (Tabela 2). A primeira do ranking foi a cultivar 'BRS Ponteio'. Das testemunhas, a cultivar 'Comum' ficou no grupo de maior produção. A produção acumulada obtida para todas as populações pode ser considerada baixa. Outros trabalhos desenvolvidos na região do Litoral Sul do Rio Grande do Sul mostram valores de até $5700 \mathrm{~kg} \mathrm{ha}^{-1}$ (GOMES \& REIS, 1999); entretanto, os autores detectaram grande variação entre anos, atribuída a diferenças climáticas. Grande variação de produtividade entre anos foi detectada também no Planalto Catarinense (TCACENCO, 1995).

Quanto aos caracteres avaliados apenas na quarta repetição, o ciclo variou de 115 a 166 dias, a altura final das plantas de 63,0 a $87,3 \mathrm{~cm}$; e a produção de sementes de 54,2 a $395,9 \mathrm{~kg} \mathrm{ha}^{-1}$ (Tabela 3). Nas gramíneas em geral, especialmente em cereais, o ciclo possui alta herdabilidade, conforme detectado em trigo (EHDAINE \& WAINES, 1989), aveia (PETR \& FREY, 1966; MITTELMANN et al., 2001) e cevada (FREY, 1954). Também para o azevém as herdabilidades realizadas geralmente são altas (NELSON et al., 1997). Portanto, a amplitude de variação de 51 dias observada neste experimento representa uma interessante possibilidade de 
Tabela 2 - Médias de populações de azevém para vigor inicial, hábito de crescimento e produção de matéria seca (MS, $\left.\mathrm{kg} \mathrm{ha}{ }^{-1}\right)$ em cinco cortes e acumulada. Capão do Leão, 2004

\begin{tabular}{|c|c|c|c|c|c|c|c|c|}
\hline \multirow[b]{2}{*}{ População } & \multirow[b]{2}{*}{ Vigor } & \multirow[b]{2}{*}{ Hábito } & \multicolumn{6}{|c|}{ 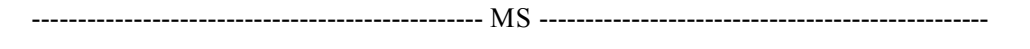 } \\
\hline & & & $1^{\underline{0}}$ corte & $2^{\underline{o}}$ corte & $3^{\circ}$ corte & $4^{\circ}$ corte & $5^{\circ}$ corte & Acumulada \\
\hline BRS Ponteio & $4,13 \mathrm{a}$ & $4,33 \mathrm{a}$ & $353,33 a$ & $834,67 \mathrm{a}$ & $812,00 b$ & $1536,67 \mathrm{a}$ & $295,00 a$ & $3905,67 \mathrm{a}$ \\
\hline 49 & $3,25 \mathrm{a}$ & $2,67 b$ & $205,33 \mathrm{a}$ & $639,33 b$ & $755,33 b$ & $730,00 \mathrm{~b}$ & $46,60 \mathrm{~b}$ & $2378,60 \mathrm{~b}$ \\
\hline 55 & $2,88 \mathrm{a}$ & $2,33 b$ & $260,67 \mathrm{a}$ & $766,00 \mathrm{a}$ & $771,33 b$ & $830,67 b$ & $139,00 \mathrm{a}$ & $2767,67 b$ \\
\hline 74 & $3,63 \mathrm{a}$ & $4,00 \mathrm{a}$ & $310,00 \mathrm{a}$ & $698,00 \mathrm{a}$ & $970,00 \mathrm{a}$ & $1178,00 \mathrm{a}$ & $224,13 \mathrm{a}$ & $3380,13 \mathrm{a}$ \\
\hline 77 & $2,38 \mathrm{a}$ & $2,33 b$ & $186,00 \mathrm{a}$ & $488,67 b$ & $561,33 b$ & $880,00 \mathrm{~b}$ & $205,87 \mathrm{a}$ & $2321,87 b$ \\
\hline 78 & $3,38 \mathrm{a}$ & $3,00 \mathrm{~b}$ & $380,67 \mathrm{a}$ & $739,33 a$ & $906,67 \mathrm{a}$ & $1161,33 \mathrm{a}$ & $146,80 \mathrm{a}$ & $3334,80 \mathrm{a}$ \\
\hline 80 & $3,63 \mathrm{a}$ & $3,33 b$ & $306,00 \mathrm{a}$ & $801,33 a$ & $862,67 b$ & $832,00 \mathrm{~b}$ & $60,40 \mathrm{~b}$ & $2862,40 \mathrm{~b}$ \\
\hline 102 & $3,50 \mathrm{a}$ & $2,67 b$ & $266,67 \mathrm{a}$ & $602,00 \mathrm{~b}$ & $746,67 b$ & $1178,00 \mathrm{a}$ & $333,47 \mathrm{a}$ & $3126,80 \mathrm{a}$ \\
\hline 103 & $3,00 \mathrm{a}$ & $5,00 \mathrm{a}$ & $332,00 \mathrm{a}$ & $904,67 \mathrm{a}$ & $973,33 \mathrm{a}$ & $686,00 \mathrm{~b}$ & $88,07 \mathrm{~b}$ & $2984,07 b$ \\
\hline 130 & $3,17 \mathrm{a}$ & $5,00 \mathrm{a}$ & $386,67 \mathrm{a}$ & $826,00 \mathrm{a}$ & $1044,67 \mathrm{a}$ & $938,00 \mathrm{~b}$ & $220,73 a$ & $3416,07 a$ \\
\hline 133 & $3,13 \mathrm{a}$ & $4,00 \mathrm{a}$ & $287,33 \mathrm{a}$ & $801,33 \mathrm{a}$ & $1074,00 \mathrm{a}$ & $1128,00 \mathrm{a}$ & $133,00 \mathrm{a}$ & $3423,67 a$ \\
\hline 135 & $3,63 \mathrm{a}$ & $3,33 b$ & $307,33 \mathrm{a}$ & $812,00 \mathrm{a}$ & $1006,00 \mathrm{a}$ & $772,00 \mathrm{~b}$ & $233,30 a$ & $2687,30 \mathrm{~b}$ \\
\hline 139 & $3,00 \mathrm{a}$ & $4,33 \mathrm{a}$ & $226,00 \mathrm{a}$ & $707,33 \mathrm{a}$ & $878,00 \mathrm{a}$ & $607,33 \mathrm{~b}$ & $103,07 \mathrm{a}$ & $2521,73 b$ \\
\hline 141 & $3,50 \mathrm{a}$ & $4,33 \mathrm{a}$ & $262,00 \mathrm{a}$ & $525,00 \mathrm{~b}$ & $1067,33 \mathrm{a}$ & $1295,33 \mathrm{a}$ & $161,33 \mathrm{a}$ & $3536,00 \mathrm{a}$ \\
\hline 142 & $3,13 \mathrm{a}$ & $4,33 \mathrm{a}$ & $294,67 \mathrm{a}$ & $838,67 \mathrm{a}$ & $906,00 \mathrm{a}$ & $628,67 b$ & $52,53 \mathrm{~b}$ & $2720,53 b$ \\
\hline 143 & $3,25 \mathrm{a}$ & $5,00 \mathrm{a}$ & $254,67 \mathrm{a}$ & $752,00 \mathrm{a}$ & $1012,00 \mathrm{a}$ & $736,67 b$ & $46,80 \mathrm{~b}$ & $2942,13 b$ \\
\hline 144 & $3,25 \mathrm{a}$ & $5,00 \mathrm{a}$ & $267,33 \mathrm{a}$ & $844,00 \mathrm{a}$ & $1171,33 \mathrm{a}$ & $881,33 b$ & $75,73 \mathrm{~b}$ & $3239,73 \mathrm{a}$ \\
\hline 149 & $3,50 \mathrm{a}$ & $5,00 \mathrm{a}$ & $277,33 a$ & $912,67 \mathrm{a}$ & $994,67 a$ & $837,33 b$ & $47,27 b$ & $3069,27 \mathrm{a}$ \\
\hline 155 & $3,25 \mathrm{a}$ & $2,67 b$ & $246,67 \mathrm{a}$ & $646,00 \mathrm{~b}$ & $978,00 \mathrm{a}$ & $1393,33 \mathrm{a}$ & $137,40 \mathrm{a}$ & $3401,40 \mathrm{a}$ \\
\hline 156 & $2,63 \mathrm{a}$ & $3,00 \mathrm{~b}$ & $205,33 \mathrm{a}$ & $599,33 \mathrm{~b}$ & $831,33 b$ & $1458,67 \mathrm{a}$ & $203,27 \mathrm{a}$ & $3297,93 \mathrm{a}$ \\
\hline 157 & $2,50 \mathrm{a}$ & $3,00 \mathrm{~b}$ & $187,33 \mathrm{a}$ & $630,67 b$ & $924,67 \mathrm{a}$ & $1381,33 \mathrm{a}$ & $67,30 \mathrm{~b}$ & $3325,93 \mathrm{a}$ \\
\hline 158 & $2,75 \mathrm{a}$ & $3,00 \mathrm{~b}$ & $224,00 \mathrm{a}$ & $633,33 b$ & $876,67 \mathrm{a}$ & $1294,00 \mathrm{a}$ & $138,73 \mathrm{a}$ & $3166,73 \mathrm{a}$ \\
\hline 159 & $3,50 \mathrm{a}$ & $4,33 \mathrm{a}$ & $220,00 \mathrm{a}$ & $615,33 \mathrm{~b}$ & $772,67 b$ & $952,67 b$ & $72,87 b$ & $2633,53 b$ \\
\hline 160 & $3,13 \mathrm{a}$ & $5,00 \mathrm{a}$ & $286,67 \mathrm{a}$ & $823,33 \mathrm{a}$ & $960,67 \mathrm{a}$ & $784,67 b$ & $101,60 \mathrm{~b}$ & $2956,93 \mathrm{~b}$ \\
\hline 161 & $3,25 \mathrm{a}$ & $3,33 b$ & $281,33 \mathrm{a}$ & $705,33 \mathrm{a}$ & $761,33 b$ & $1088,00 \mathrm{a}$ & $82,20 \mathrm{~b}$ & $2918,20 \mathrm{~b}$ \\
\hline 162 & $3,13 \mathrm{a}$ & $3,00 \mathrm{~b}$ & $274,00 \mathrm{a}$ & $650,00 \mathrm{~b}$ & $758,00 \mathrm{~b}$ & $804,00 \mathrm{~b}$ & $149,50 \mathrm{a}$ & $2600,33 b$ \\
\hline 163 & $3,50 \mathrm{a}$ & $5,00 \mathrm{a}$ & $322,67 \mathrm{a}$ & $905,33 \mathrm{a}$ & $1071,33 \mathrm{a}$ & $836,00 \mathrm{~b}$ & $140,90 \mathrm{a}$ & $3475,90 a$ \\
\hline 164 & $3,50 \mathrm{a}$ & $4,33 \mathrm{a}$ & $337,33 \mathrm{a}$ & $850,00 \mathrm{a}$ & $842,00 \mathrm{~b}$ & $898,00 \mathrm{~b}$ & $72,13 b$ & $3334,80 \mathrm{a}$ \\
\hline CPPSUL 001 & $2,63 a$ & $2,00 \mathrm{~b}$ & $164,67 \mathrm{a}$ & $469,33 b$ & $668,67 b$ & $1052,67 \mathrm{a}$ & $227,00 \mathrm{a}$ & $2582,33 b$ \\
\hline Casca & $3,25 \mathrm{a}$ & $3,33 b$ & $210,00 \mathrm{a}$ & $698,00 \mathrm{a}$ & $1147,33 \mathrm{a}$ & $1333,33 \mathrm{a}$ & $201,93 \mathrm{a}$ & $3590,60 \mathrm{a}$ \\
\hline Hulha Negra & $3,63 \mathrm{a}$ & $2,67 b$ & $200,00 \mathrm{a}$ & $673,33 b$ & $912,67 \mathrm{a}$ & $1465,33 \mathrm{a}$ & $264,27 \mathrm{a}$ & $3515,60 \mathrm{a}$ \\
\hline Lavras & $2,67 \mathrm{a}$ & $2,00 \mathrm{~b}$ & $151,33 \mathrm{a}$ & $488,67 b$ & $686,67 b$ & $1178,00 \mathrm{a}$ & $348,80 \mathrm{a}$ & $2252,80 \mathrm{~b}$ \\
\hline São Gabriel & $2,75 \mathrm{a}$ & $2,33 b$ & $180,00 \mathrm{a}$ & $604,00 \mathrm{~b}$ & $780,00 \mathrm{~b}$ & $1137,33 \mathrm{a}$ & $192,87 \mathrm{a}$ & $2894,20 \mathrm{~b}$ \\
\hline Sarandi & $2,38 \mathrm{a}$ & $2,00 \mathrm{~b}$ & $134,00 \mathrm{a}$ & $504,00 \mathrm{~b}$ & $713,33 b$ & $1311,33 \mathrm{a}$ & $258,27 \mathrm{a}$ & $2920,93 b$ \\
\hline Trovão & $3,00 \mathrm{a}$ & $4,33 \mathrm{a}$ & $238,00 \mathrm{a}$ & $772,67 \mathrm{a}$ & $933,33 \mathrm{a}$ & $1113,00 \mathrm{a}$ & $129,53 \mathrm{a}$ & $3289,20 \mathrm{a}$ \\
\hline Vacaria & $2,75 \mathrm{a}$ & $2,33 b$ & $123,33 \mathrm{a}$ & $535,33 \mathrm{~b}$ & $614,00 \mathrm{~b}$ & $444,00 \mathrm{~b}$ & $10,70 \mathrm{c}$ & $1752,53 \mathrm{~b}$ \\
\hline Comum & $3,13 \mathrm{a}$ & $5,00 \mathrm{a}$ & $290,00 \mathrm{a}$ & $854,67 \mathrm{a}$ & $1000,67 \mathrm{a}$ & $801,33 b$ & $64,27 b$ & $3010,93 \mathrm{a}$ \\
\hline LE 284-1 & $2,00 \mathrm{a}$ & $2,67 b$ & $100,67 \mathrm{a}$ & $361,33 b$ & $993,00 \mathrm{a}$ & $810,00 \mathrm{~b}$ & $89,87 b$ & $2710,30 \mathrm{~b}$ \\
\hline LE 284-2 & $3,63 \mathrm{a}$ & $3,33 b$ & $143,33 \mathrm{a}$ & $574,67 \mathrm{~b}$ & $726,67 b$ & $1056,00 \mathrm{a}$ & $39,93 \mathrm{~b}$ & $2452,70 \mathrm{~b}$ \\
\hline
\end{tabular}

Médias seguidas da mesma letra não diferem significativamente pelo teste de Scott-Knott a $5 \%$ de probabilidade.

prolongamento do período de utilização da pastagem, uma vez que após o florescimento há perda de qualidade nutritiva e de capacidade de rebrote das plantas. A cultivar 'Comum' foi uma das mais precoces e apenas uma das procedências da cultivar 'LE 284' esteve entre as populações mais tardias. A incidência de doenças foi baixa, e algumas populações não foram avaliadas por já estarem em processo de senescência quando os sintomas se manifestaram nas demais.

Um fato a ser observado é a diferença de comportamento entre as duas procedências da cultivar 'LE 284', evidenciada por diferenças significativas para os caracteres produção de matéria seca no terceiro e quarto cortes, além de uma diferença de doze dias na duração do ciclo vegetativo. A cultivar 'LE 284' é uma 
cultivar antiga, lançada na década de 1950 no Uruguai, e é de domínio público no Brasil, sendo hoje multiplicada e comercializada por inúmeros produtores. Assim, podemos considerar que esta variedade vem perdendo sua identidade genética. Isso pode ter ocorrido por seleção ou deriva, levando em conta a alta variabilidade intrapopulacional que é característica da espécie e o longo tempo em cultivo; pelo cruzamento com outras populações ou mesmo por mistura de sementes. Todos estes fatores são apontados por CARAMBULA (1981) como dificuldades na produção de sementes forrageiras.

A análise de distâncias fenotípicas mostrou que as populações mais semelhantes foram a 103 e a 'Comum', com estimativa de distância euclidiana média de 0,3549. Estas populações têm em comum a alta produtividade nos três primeiros cortes, com acentuada queda nos dois últimos, o que está relacionado ao seu florescimento precoce (Tabelas 2 e 3). Também são originárias da mesma região, no Noroeste do Estado

Tabela 3 - Valores de ciclo (dias), altura final de planta $(\mathrm{cm})$, severidade de ferrugem do colmo e de doenças foliares (\%) e produção de sementes $\left(\mathrm{kg} \mathrm{ha}^{-1}\right)$ em populações de azevém. Capão do Leão, 2004.

\begin{tabular}{|c|c|c|c|c|c|}
\hline População & Ciclo & Altura final & Ferrugem & Doenças foliares & Produção de sementes \\
\hline BRS Ponteio & 148 & 69,7 & $2 \%$ & $2 \%$ & 235,9 \\
\hline 49 & 146 & 73,3 & não avaliada & não avaliada & 143,8 \\
\hline 55 & 150 & 67,3 & não avaliada & não avaliada & 155,3 \\
\hline 74 & 157 & 63,7 & $3 \%$ & $3 \%$ & 198,2 \\
\hline 77 & 166 & 65,0 & não avaliada & não avaliada & 73,1 \\
\hline 78 & 146 & 86,0 & $3 \%$ & $2 \%$ & 128,3 \\
\hline 80 & 147 & 86,3 & $2 \%$ & $2 \%$ & 150,0 \\
\hline 102 & 157 & 78,7 & $2 \%$ & $3 \%$ & 155,7 \\
\hline 103 & 123 & 63,0 & $2 \%$ & $2 \%$ & 395,9 \\
\hline 130 & 126 & 72,7 & $2 \%$ & $2 \%$ & 125,7 \\
\hline 133 & 135 & 71,0 & não avaliada & não avaliada & 360,6 \\
\hline 135 & 146 & 80,7 & $2 \%$ & $5 \%$ & 223,1 \\
\hline 139 & 135 & 73,3 & $2 \%$ & $5 \%$ & 246,2 \\
\hline 141 & 132 & 87,3 & não avaliada & não avaliada & 339,4 \\
\hline 142 & 119 & 80,0 & $2 \%$ & $3 \%$ & 201,4 \\
\hline 143 & 115 & 67,7 & não avaliada & não avaliada & 244,2 \\
\hline 144 & 137 & 81,7 & $2 \%$ & $2 \%$ & 218,4 \\
\hline 149 & 128 & 80,3 & não avaliada & não avaliada & 106,8 \\
\hline 155 & 145 & 82,3 & $0 \%$ & $3 \%$ & 275,8 \\
\hline 156 & 144 & 84,0 & $0 \%$ & $2 \%$ & 221,6 \\
\hline 157 & 151 & 72,7 & $2 \%$ & $2 \%$ & 274,9 \\
\hline 158 & 153 & 66,7 & $2 \%$ & $2 \%$ & 197,0 \\
\hline 159 & 127 & 74,0 & não avaliada & não avaliada & 189,4 \\
\hline 160 & 133 & 70,7 & $0 \%$ & $2 \%$ & 191,8 \\
\hline 161 & 144 & 70,7 & não avaliada & não avaliada & 123,1 \\
\hline 162 & 152 & 75,7 & $0 \%$ & $3 \%$ & 134,9 \\
\hline 163 & 125 & 82,7 & $2 \%$ & $7 \%$ & 228,8 \\
\hline 164 & 130 & 70,0 & não avaliada & não avaliada & 254,3 \\
\hline CPPSUL 001 & 165 & 67,3 & $2 \%$ & $2 \%$ & 54,2 \\
\hline Casca & 140 & 83,3 & $0 \%$ & $2 \%$ & 227,2 \\
\hline Hulha Negra & 160 & 80,3 & $2 \%$ & $8 \%$ & 113,4 \\
\hline Lavras & 162 & 81,3 & $0 \%$ & $8 \%$ & 64,4 \\
\hline São Gabriel & 151 & 78,7 & $2 \%$ & $6 \%$ & 155,1 \\
\hline Sarandi & 155 & 68,0 & $2 \%$ & $3 \%$ & 117,2 \\
\hline Trovão & 137 & 75,3 & $2 \%$ & $7 \%$ & 59,2 \\
\hline Vacaria & 158 & 64,0 & não avaliada & não avaliada & 58,9 \\
\hline Comum & 120 & 66,3 & $0 \%$ & $2 \%$ & 166,9 \\
\hline LE 284-1 & 157 & 77,3 & $0 \%$ & $3 \%$ & 83,9 \\
\hline LE 284-2 & 145 & 77,3 & $2 \%$ & $3 \%$ & 131,7 \\
\hline
\end{tabular}

não avaliada $=$ populações que já se encontravam em senescência quando os sintomas iniciaram no experimento. 
do Rio Grande do Sul. A duração do ciclo vegetativo é um dos principais fatores relacionados à distribuição da produção de forragem no azevém (NELSON et al., 1997). As populações mais divergentes foram 'BRS Ponteio' e LE 284-1, com 2,7227. A média das estimativas de distância foi de 1,3444. Dois grandes grupos de populações foram formados (Figura 1). LE284-1, Vacaria, CPPSUL001, Lavras, Sarandi e 77 formaram o Grupo I e as demais populações, o Grupo II. As populações do Grupo I têm em comum as produtividades de matéria seca mais baixas nos cortes 1 e 2 , associadas a um ciclo vegetativo mais longo (Tabelas 2 e 3). Porém, não necessariamente figuram entre as mais produtivas para os cortes finais.

Os caracteres que mais contribuíram para a divergência foram todos relacionados à produtividade, com destaque para a produtividade de matéria seca no quarto corte, responsável por $57,82 \%$ da variação (Tabela 4). Este corte corresponde ao início da primavera, onde o azevém alcança as maiores produtividades (CARAMBULA, 1977), o que exacerba as diferenças entre cultivares. A alta influência dos cortes neste período foi detectada também por MITTELMANN et al. (2004). O vigor inicial e o hábito de crescimento tiveram contribuição insignificante para a divergência. Sistemas de produção, envolvendo rotação com culturas de verão ou que utilizam o azevém apenas para cobertura de solo, exigem cultivares de ciclo curto. Sistemas com ênfase na pecuária são favorecidos com cultivares de azevém de ciclo longo. $\mathrm{O}$ agrupamento das populações com base nas características de produção de forragem pode auxiliar o melhoramento no sentido da seleção de populações, planejamento de cruzamentos ou da formação de compostos direcionados aos diferentes sistemas de produção.

\section{CONCLUSÃO}

As populações locais de azevém diferem entre si para a produção acumulada de matéria seca, bem como para sua distribuição ao longo do ciclo. Estas características foram importantes para a

Tabela 4 - Contribuição relativa dos caracteres para a divergência entre populações de azevém, determinada conforme SINGH (1981). Capão do Leão, 2004.

\begin{tabular}{|c|c|}
\hline Caráter & Contribuição relativa $(\%)$ \\
\hline Vigor & 0,0002 \\
\hline Hábito & 0,0008 \\
\hline MS $1^{\circ}$ corte $\left(\mathrm{kg} \mathrm{ha}^{-1}\right)$ & 3,9246 \\
\hline MS $2^{-}$corte $\left(\mathrm{kg} \mathrm{ha}^{-1}\right)$ & 15,2645 \\
\hline MS $3^{\circ}$ corte $\left(\mathrm{kg} \mathrm{ha}^{-1}\right)$ & 16,9501 \\
\hline MS $4^{\circ}$ corte $\left(\mathrm{kg} \mathrm{ha}^{-1}\right)$ & 57,8203 \\
\hline MS $5^{\circ}$ corte $\left(\mathrm{kg} \mathrm{ha}^{-1}\right)$ & 5,8543 \\
\hline Ciclo (dias) & 0,1461 \\
\hline Altura $(\mathrm{cm})$ & 0,0390 \\
\hline
\end{tabular}

$\mathrm{MS}=$ produção de matéria seca

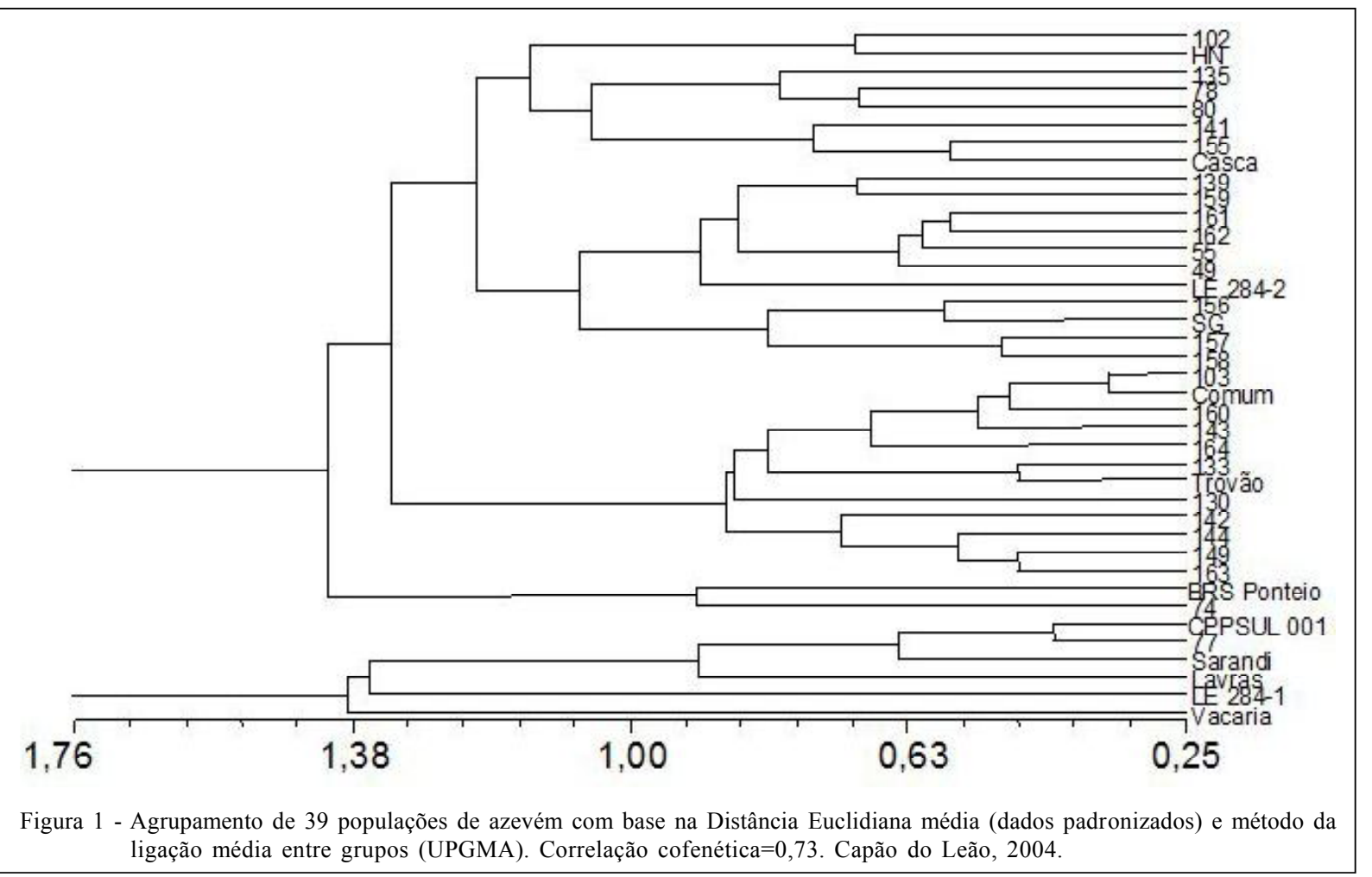

Ciência Rural, v.40, n.12, dez, 2010. 
divergência e o agrupamento das populações, podendo auxiliar decisões estratégicas nos programas de melhoramento.

\section{REFERÊNCIAS}

CARAmbula, M. Producción y manejo de pasturas sembradas. Montevideu: Hemisferio Sur, 1977. 476p.

CARAmbula, M. Producción de semillas de plantas forrajeras. Montevideu: Hemisferio Sur, 1981. 518p.

CASTRO, C.M. et al. Morphological and molecular characterization of Italian ryegrass populations. Crop Breeding and Applied Biotechnology, v.3, n.4, p.245254, 2003. Disponível em: <http://www.sbmp.org.br/cbab/ siscbab $/$ modules $/$ news $/$ makepdf.php? storyid=174>. Acesso em: 22 set. 2010.

CRUZ, C.D. Programa Genes versão Windows: aplicativo computacional em genética e estatística. Viçosa: UFV, 2001. $642 \mathrm{p}$.

DIAS, J.C.A. et al. Avaliação de genótipos de azevém anual em solos hidromórficos. Pelotas: Embrapa Clima Temperado, 2001. 2p. (Embrapa Clima Temperado. Comunicado Técnico, 42).

EASTON, H.S. Ryegrasses. In: WRATT, G.S.; SMITH, H.C. Plant breeding in New Zealand. Wellington: Butterworths (D.S.I.R.), 1980. p. 229-236.

EHDAINE, B.; WAINES, J.G. Genetic variation, heritability and path analysis in landraces of bread wheat from south western Iran. Euphytica, v.41, p.183-190, 1989. Disponível em: $<$ http://www.springerlink.com/content/t8687351t12018m4/ fulltext.pdf $>$. Acesso em: 22 set. 2010. doi: 10.1007/ BF00021584.

EMPRESA BRASILEIRA DE PESQUISA AGROPECUÁRIA EMBRAPA. Sistema brasileiro de classificação de solos. Brasília: EMBRAPA, 1999. 412p.

FRANKEL, O.H. et al. The conservation of plant biodiversity. Cambridge: Cambridge University, 1995.

FREY, K.J. Inheritance and heritability of heading date in barley. Agronomy Journal, v.46, p.226-228, 1954. Disponível em: https://www.agronomy.org/publications/aj/pdfs/ 46/5/AJ0460050226. Acesso em: 22 set. 2010. doi: doi:10.2134/agronj1954.00021962004600050011x.

GOMES, J.F.; REIS, J.C.L. Produção de forrageiras anuais de estação fria no Litoral Sul do Rio Grande do Sul. Revista Brasileira de Zootecnia, v.28, p.668-674, 1999. Disponível em: <http://www.revistasbz.org.br/scripts/revista/sbz1/Artigos/ 2310.PDF>. Acesso em: 22 set. 2010.
MITTELMANN, A. et al. Herdabilidade para os caracteres ciclo vegetativo e estatura de planta em aveia. Ciência Rural, v.31, n.6, p.999-1002, 2001. Disponível em: http:// www.scielo.br/pdf/cr/v31n6/a13v31n6.pdf. Acesso em: 22 set. 2010. doi: $10.1590 / \mathrm{S} 0103-84782001000600013$

mittelmann, A. et al. Avaliação de populações de azevém quanto à produção de forragem. Juiz de Fora: Embrapa Gado de Leite, 2004. 12p. (Embrapa Gado de Leite. Boletim de Pesquisa, 15).

MITTELMANN, A. O melhoramento de azevém na Embrapa. In: MITTELMANN, A. et al. (Eds.). Seminário caminhos do melhoramento de forrageiras, e dia de campo de melhoramento de forrageiras: palestras. Pelotas: Embrapa Clima Temperado, 2005. 86p. (Embrapa Clima Temperado. Série Documentos, 140).

MITTELMANN, A. et al. Indirect selection of forage production in Italian ryegrass. Crop Breeding and Applied Biotechnology, v.6, n.1, p.104-106, 2006. Disponível em: $<$ http://www.sbmp.org.br/cbab/siscbab/modules/news/ article.php? storyid=353>. Acesso em: 22 set. 2010 .

NELSON, L.R. et al. Plant breeding for improved production in annual ryegrass. In: ROUQUETTE Jr., F.M.; NELSON, L.R. (Ed.). Ecology, production, and management of Lolium for forage in the USA. Madison: CSSA, 1997. p.114.

PETR, F.C.; FREY, K.J. Genotypic correlations, dominance, and heritability of quantitative characters in oats. Crop Science, v.6, p.259-262, 1966. Disponível em: <https://www.crops.org/ publications/cs/pdfs/6/3/CS0060030259>. Acesso em: 22 set. 2010. doi:10.2135/cropsci1966.0011183X000600030013x.

ROSSO, B.S.; ANDRÉS, A. Preliminary evaluation of naturalized Italian ryegrass populations in Buenos Aires province, Argentina. Plant Genetic Resources Newsletter, n.128, p.51-54, 2001. Disponível em: <http:// www2.bioversityinternational.org/publications/pgrnewsletter/ article.asp? lang $=$ en\&id article $=34 \& i d$ issue $=128>$. Acesso em: 22 set. 2010.

SAS INSTITUTE. SAS/STAT user's guide. Version 6.4 ed. Cary: SAS Institute, 1990. 1848p.

SINGH, D. The relative importance of characters affecting genetic divergence. Indian Journal of Genetics and Plant Breeding, v.41, n.2, p.237-245, 1981.

TCACENCO, F.A. Comparação de cultivares de azevém anual em Lages, Estado de Santa Catarina. Pesquisa Agropecuária Brasileira, v.24, p.157-163, 1989

TCACENCO, F.A. Desempenho de cultivares de Lolium multiflorum Lam. em Lages, Santa Catarina. Pesquisa Agropecuária Gaúcha, v.1, n.1, p.119-123, 1995. 